\title{
Intercultural Training is a culture specific interaction process
}

\author{
Alexander Thomas
}

\section{Introduction}

Not only psychology, but also science in general is quite clearly completely dominated by a Euro- or US-centred view. A researcher in the field of psychology, for example, who strives for international recognition, must, no matter where he comes from or where he works, have knowledge of western psychology and keep its ideas in mind. He is practically forced to completely adapt his own scientific thoughts and actions to this foreign view. Of course, today's modern, open-minded, globally-thinking, internationally orientated psychologist now demands a stronger recognition and development of "indigenous psychology", a psychology rooted in the people's national-, ethnicand subcultural background. These demands, however, though nothing new, have not yet had any consequences in practice for international scientific psychology.

\section{The "culture assimilator training"}

The conception of the culture assimilator training poses an excellent example of the importance of culture-specific influence on cross-cultural trainings.

The culture assimilator training was developed in 1962 at the University of Illinois by the psychologists Fiedler, Osgood, Triandis and Stolurow (Albert, 1983; Fiedler, Mitchell \& Triandis, 1971) as an cross-cultural orientation programme for students. In the following, further culture-specific orientation programmes as well as culture-general trainings based on the culture assimilator method were developed and their usefulness evaluated. To date, the culture assimilator concept is the internationally most applied and evaluated crosscultural training. Its strength lies in a clear and easily-understandable structure. A culture assimilator consists of a varying number of real-life scenarios which are worked on in the following manner:

1. A short episode is presented which describes a typical intercultural interaction between a member of one's own and a member of a foreign culture. This situation is in some way problematic, meaning that a misunderstanding will probably occur. 
2. After reading the episode, the user is offered three, four or more alternative explanations for the involved persons' behaviour, out of which he is asked to choose the one he finds best explains the situation from the foreign partner's point of view. Usually, only one alternative precisely captures the foreign person's point of view. The others, while seeming adequate from one's own cultural background, do not offer a correct explanation.

3. After the learner has selected one of the alternatives, he is given feedback regarding his choice. If he has chosen correctly, the feedback is positive. After receiving additional information about the role culture plays in such situations, he may continue with the next episode. If the choice was incorrect, it is explained exactly why this interpretation was wrong. The learner is then asked to re-read the episode and select a different alternative. (Lange, 1994)

For people who are faced with coping with a foreign environment, the culture assimilator fulfils several basic needs:

1. Prior to going abroad, people often feel very insecure and frightened knowing that they will have to master critical cross-cultural interactions. The culture assimilator offers the possibility to get to know such situations and practice necessary skills in advance (need for orientation, learning and achievement)

2. The inevitable complexity of real-life situations is reduced to a simple "Have I found the wrong or right answer?" (need for simplicity/transparency, need for objectivity).

3. Explanations are offered for each and every one of the alternatives, highlighting both what the trainee has done wrong, what he has missed and what he must pay especial attention to later on. Also, he receives feedback on which of his choices were right and why exactly they were right (need for learning).

4. Having to solve 50 to 100 such critical situations, the learner usually strives to answer as many as possible correctly the first time, or, at least the second time round. The assimilator becomes a sort of competitive game in which one tries to reach a higher score than others (need for competition, comparison, optimisation). This competitiveness, however, results in the somewhat problematic situation that those learners who chose the correct alternative at the first try (with a $25 \%$ chance of guessing correctly) draw the least profit from what the training has to offer. Those who guess incorrectly, however, read the background information for more than one alternative, thus all in all receive more information.

5. When the corrects answers are chosen, meaning those containing culturally "isomorphic attributions" (Triandis, 1975), learners receive positive feedback (need to raise ones self-esteem) 
Each unit of a culture assimilator starts off with a gripping, usually very complex example of a problematic cross-cultural situation. But instead of thoroughly analysing the episode, viewing it from different perspectives, discussing possible explanations or reactions which might follow, the learner is forced into a simplified yes or no-pattern. All the situation's potential for helping to change one's own perspective and thus reach a more profound level of crosscultural learning is put aside, only to have an objective measurement of achievement (Landis \& Bhagat, 1996).

\section{US cultural standards and the culture assimilator training}

Summing up existing studies which compare US cultural standards with those of other nations (e.g. Müller \& Thomas, 1995; Markowsky \& Thomas, 1995), the following US cultural standards can be extracted:

Fig. 1: Central US cultural standards

\begin{tabular}{|l|} 
1. Individualism \\
2. Action/ Goal orientation \\
3. Achievement orientation \\
4. Equality of chances \\
5. Social support \\
6. Pragmatism \\
7. Minimisation of interpersonal distance \\
8. Patriotism \\
9. Mobility \\
\hline
\end{tabular}

Cultural standards can be defined as specific ways of perceiving, thinking, judging and acting, which are seen as normal and naturally obligatory by members of a certain culture (Thomas, 1993). Thus, both the developers as well as the users of intercultural trainings are influenced by their own cultural standards. Not surprisingly, the concept of the culture assimilator training precisely reflects the first six US cultural standards:

The training is completed individually. The goals and procedure are fixed. Achievement can be measured objectively. Everybody has the same chance of success. Correct choices are socially acknowledged. The training's material and structure show obvious links to real-life cross-cultural encounters.

For an American student or manager, the culture assimilator offers an excellent way of testing and ameliorating his cross-cultural performance prior to going abroad:

1. The culture assimilator can be worked on individually, either as a pencil and paper test or at a computer. The critical interactions, alternative explanations and background information will give him an idea of his learning progress 
and how capable he is of discovering the culturally correct solutions. Also, the culture assimilator can be integrated into a cross-cultural orientation training in which a trainer moderates group discussions.

2. The group training offers the possibility of comparing ones own cross-cultural performance with that of others. It also provides the advantage of group feedback and feedback through the trainer, as well as social acknowledgement and support through the others. As mentioned above, the culture assimilator exactly matches the US cultural standards "individualism, equal chances, action orientation, achievement orientation and social acknowledgement".

3. Through putting oneself into the other's situation, it becomes possible to understand his thoughts and feelings during the interaction, which in turn helps to adjust oneself to his needs.

4. The culture assimilator is clearly structured, transparent, uses authentic situations and can be easily understood. Anybody can grasp that this training must in some way ameliorate cross-cultural competence.

5. While not quite as over-simplified as the infamous lists of "dos and don'ts", the culture assimilator still doesn't ask overly much in the way of theory and abstraction. It can cater both to somebody who just wants a first overview on a foreign culture as well as somebody demanding more in-depth information on his own and the foreign cultural orientation system- right down to the cultural standards' socio-historic backgrounds.

An American trainee who was born and bred in an American cultural background, living by US-American cultural standards, thus feels regarding training and achievement are taken care of. But what impression does such a training make on a learner from another culture, for example a German or Czech trainee?

\section{German Cultural Standards and the Culture Assimilator Training}

In Germany the culture assimilator is an accepted and commonly used crosscultural training method. Not surprisingly, though, it also matches several German cultural standards (fig. 2).

These German cultural standards are derived from interviews conducted with business partners from another culture about their experiences with Germans, either during their stay in Germany or in their own countries. The interviewees were recruited e.g. from the USA, France, Britain, the Czech Republic, China, Korea, Japan, Indonesia and Argentina.

Germans usually view the analysis of critical incidents, on which the culture assimilator is based, to be an extremely effective way of preparing oneself for a stay abroad (fact-orientation). The cultural standards are a great help to learn 
how to behave in a foreign culture or towards foreigners in Germany (ruleorientation). After the training, the learner feels much more secure and has an idea of what to expect. The culture assimilator, which is seen to be clearly structured, transparent and obviously tailored to fit the culture the trainee is interested in, assumes the role of a guide and leader (hierarchy and authority orientation).

Fig. 2: German Cultural Standards

1. Fact-orientation

2. Rule-orientation

3. Direct interpersonal communication

4. Interpersonal distance differentiation

5. Hierarchy and authority orientation

6. Time planning

German students, scientists and language teachers however often criticise its tendency towards simplifying and generalising instead of facing the complexity of real life (e.g. one "right", three "wrong answers). Cultural standards are regarded as being much too stereotype to be able to explain something as dynamic as cross-cultural encounters. The wish to analyse and understand the described scenarios and their dynamics could not be fulfilled through so called stereotypes, which do nothing but create or strengthen prejudice against people from other cultures. Therefore, the department for Social- and Organisational Psychology of the University of Regensburg began to develop culture assimilators in a slightly modified form. Rather than offering three "wrong" and one "right" answers, as in the US-American standard version, the trainee is asked to judge the degree to which he believes the answer to be a correct explanation for the incident. He thus rates how culturally isomorphic he believes an answer to be on a four-point scale ranging from "most probable", "possible", "improbable", "least probable". Also, the cultural standards are no longer expressed and described by only a single word. Several sentences explain the exact meaning of a cultural standard, as well as its historic and cultural development and background. Furthermore, possible culturally adequate solutions for the described critical incidents are provided.

Basically, the culture assimilator may be worked on either individually or in a group. Group discussions have proven very effective and productive in trainings for German students or business people. The critical incidents as well as the possible answers are analysed and discussed intensively and in depth. This finding is in line with other cross-cultural studies e.g. on problem solving in groups, which show Germans to enjoy discussing a problem extensively until the heart of the problem, its "inner core", is discovered. American groups, on the other hand, are much more prepared to make do with temporary solutions, which 
are then tested, modified if necessary and tested again, before finally arriving at a workable, usually socially accepted, solution (Schroll-Machl, 1996; Stumpf \& Thomas, 2000; Zeutschel, 1999).

\section{Czech Cultural Standards and the Culture Assimilator Training}

The following Czech cultural standards were identified in an empirical study by Sylvia Schroll-Machl (2000a, b), which analysed ifferences between German and Czech cultural standards.

Fig. 3: Czech cultural standards (as seen by German managers)

1. Personal relationship/importance of face-to-face interaction

2. Depreciation of structures

3. Simultaneity

4. Control by people

5. Diffusion of work- and personal domains

6. Implicit communication (Context-orientation)

7. Evasion of conflicts

8. Fluctuating self-confidence

The culture assimilator is a clearly structured training method which aims to increase the user's knowledge and understanding about another culture. Also, his behavioural competency in encounters with foreign partners should be improved. The Czech culture, however, sees good connections and relationships to others (personal relationship) as indispensable for reaching goals, for success and productivity. Thus, a training which has nothing to do with building connections to others will seem rather useless.

"Czechs usually dislike fixed structures and therefore only sometimes keep to them, preferring instead to improvise. They regard being flexible, subtle, clever and creative as key characteristics of their own culture. Every situation is made use of which offers the chance to improvise" (Schroll-Machl, 2000a, p. 79). Due to the cultural standard "depreciation of structures", a culture assimilator in written form is also viewed sceptically. Positive reactions are only to be expected if the culture assimilator is introduced as discussion material. Also, it may be presented at the very end of a training, after all participants have been allowed sufficient time to explain their individual point of view on the critical incidents and the different explanations.

Additionally, the culture standards "depreciation of structures", "evasion of conflicts", "fluctuating self-confidence" result in a sceptical, distrustful attitude towards the culture assimilator. The fact that some kind of anonymous authority has the right to tell one which behaviour is culturally acceptable and which isn't- 
and one doesn't even have the chance to talk about what might be "a bit right" or "a bit wrong"- this is just not acceptable. The clear structure and the many explanations and descriptions provided don't create the intended serious impression. For Czech learners, more detailed descriptions of the critical incidents would be of much greater importance. In order to be able to accept such a training - to a certain degree - the critical incidents should be described in such detail so that the narrator's competency becomes evident (realistic stories). Furthermore, the situations should be very complex and offer links to specific professional fields and jobs. Also, the culture assimilator training should be incorporated into training based more on face-to-face learning. The Czech participants are willing to believe what the trainer says, but not what is given to them in writing.

The general acceptance of the culture assimilator is also reduced by the cultural standard "implicit communication (context orientation) ". Czechs prefer to hint at what they want to say, being very careful of what words they choose and how they say something: "Instead of coming right out and saying something straight out, they will use paraphrases and round-about descriptions. Rather than coming right to the point, the actual message will be preceded and camouflaged through a multitude of words. Humour is a very central aspect because it offers the possibility to hint at things, to slip in a hidden criticism or an embarrassing subject matter. During controversies and discussions, questions are often used as a stylistic element. They are employed to highlight weak arguments and thus encourage the other to chance his point of view" (Schroll-Machl, 2000a, p. 121). These intentionally used hints, metaphors and implicit, hidden information, which are generally accepted are the almost complete opposite to the culture assimilator. Its concept is to be as clear, logical and rational as possible.

Correctly used, the culture assimilator will at first make the learner feel slightly uneasy, because it questions the ways of perceiving, of judging and behaving which he is used to. He is forced to analyse them in order to then be able to add new, culturally adequate ways of perceiving, judging and behaving. Thus, such a method of cross-cultural leaning is necessarily very difficult for people with "fluctuating self-confidence". Everybody who is confronted with having to communicate and co-operate with people from foreign cultures feels insecure, especially in the very beginning. He will try to find some kind of security as fast as possible. The culture assimilator, however, doesn't offer a feeling of security at once- unlike the popular "do's and don'ts". It's aim is to help the user reflect and thus learn the subject-matter. This, however, does not take place in a communicative, free setting, via dialogues with other learners, but is restrained to working with a fixed, written format. The above-mentioned study also shows "Czechs to have a very exact sense regarding asymmetry in relationships: They experience detailed explanations to make the person receiving the explanation seem less intelligent than the other. A structured, well-prepared presentation can 
easily overrun the listener and make an overly dominant impression. Help offered is quickly regarded as being the act of a superior towards his inferior" (Schroll-Machl, 2000a, p. 136). This way of thinking influences not only relationships towards other people, but also makes accepting written training material more difficult.

Last but not least, the importance of the Czech cultural standard "simultaneity" and its influence on the acceptance of the culture assimilator training should be underlined. "In the Czech culture, it is highly desirable to do several things at the same time. This means combining different things with one another, working on several projects at once- and - the other way round- have something one does further several of these parallel projects. Also, Czechs often lack the sense of purpose and will to keep to and reach just one of this multitude of goals. Instead, they prefer to try to keep several things going and try out various different ways of solving a problem" (Schroll-Machl, 2000a, p. 99). This, however, has nothing whatsoever to do with the culture assimilator method. On the contrary, the culture assimilator demands of the learner to work on the situations and their explanations one at a time, in a consecutive manner.

Of course, people from all cultural backgrounds learn equally well and are naturally also prepared to use methods which have not been developed in their own culture. However, the differences between the principles on which the culture assimilator is based and the Czech cultural standards are tremendous. With this in mind, one needn't be surprised to find difficulties regarding its acceptance. the user's will to learn or the training's effectiveness. One will not be able to get around modifying the culture assimilator training, using it as one module in a more encompassing training, which should be discussed in a group headed by a competent, understanding trainer- thus placing more emphasis on face-to-face teaching.

Scientists and practitioners in the field of intercultural training who do not agree with what is said about the cultural specific reaction of Czech trainees against the culture assimilator training concept should use the argumentation as a kind of hypotheses for further studies.

\section{Consequences resulting for research and use of cross-cultural trainings}

Obviously, there never will be a "one size fits all"-method of cross-cultural training. Every culture has its own way handing down knowledge, of teaching the next generation everything there is to know: formal knowledge, lessons learnt from past experiences, as well as values and norms, language, religion, or rituals. Not only what is taught, the methods of teaching have been developed and handed down from generation to generation, too. In past times, e.g., it was essential to pass on hunting skills, like how to best steal up to game with one's 
bow and arrow in order to have the best chance at a kill. Similarly, today we learn how to drive a car, use an computer or do algebra- skills important for our modern life. Seen from this anthropological point of view, it hardly seems surprising that something so important for the survival and development of societies as teaching and learning should be strongly influenced by the surrounding culture. Shockingly enough, though, we know preciously little about the these cultural differences in teaching and studying methods. Globalisation, however, makes cross-cultural studies on culturally adequate teaching methods a topic of utmost importance in order to ensure that acceptable and productive ways of cross-cultural training can be provided.

An article by Bhawuk \& Brislin (2000) offers an overview on the development of different methods of cross-cultural training, their theoretical background and evaluative studies. In the last chapter, the authors attempt an outlook into possible future development in cross-cultural research and practice: "A survey of the past 50 years of the field of cross-cultural training shows that there is much enthusiasm among researchers and practitioners in this field, which is reflected, among other things, in the recent creation of the International Academy of Intercultural Research. Therefore, this field is likely to blossom manifold in the future global village, where intercultural skills will become a prime necessity" (p. 187). Also, the authors name further topics which they believe to be of increasing importance: Culture shock, evaluating cross-cultural training programmes, developing trainings and methods which are more soundly based in theory, further development of the culture assimilator method, multi-media trainings, computer-based trainings, experiential learning, as well as developing more sophisticated trainingtools from which even internationally experienced users may profit.

Finally, as I have mentioned above, every culture has developed its own methods of teaching and learning in order to pass on important knowledge to the next generation. With this in mind, it is seems almost incomprehensible why, in our increasingly international world, cross-cultural training practice and research concentrates only on Western, meaning European or US.- teaching- and learning methods. The enormous potential offered by perspectives resulting from other cultural backgrounds is ignored. The future, however, both for research and training practice, lies in intercultural training. It incorporates the fact that both partners have been prepared, which may greatly change their expectations and behaviour, as well as the impact of culture on teaching and learning methods.

\section{References}

Albert, R.D. (1983). The intercultural sensitizer or culture assimilator: A cognitive approach. In D.Landis \& R. W. Brislin (Eds.), Handbook of intercultural training, Vol. II (pp. 186-217). New York: Pergamon. 
Bhawuk, D.P.S. \& Brislin, R.W. (2000). Cross-cultural Training: A Review. In Applied Psychology: An International Review, 49 (1), 162-191.

Fiedler, F.E., Mitchell, T. \& Triandis, H.C. (1971). The culture assimilator: An approach to cross-cultural training. Journal of Applied Psychology, 55, 95-102.

Landis, D. \& Bhagat, R. (Eds.). (1996). Handbook of intercultural training. Newbury Park, CA: Sage Publications.

Lange, C. (1994). Interkulturelle Orientierung am Beispiel der Trainingsmethode "Culture Assimilator". Beiträge zur interkulturellen Didaktik, Bd. 3. Göttingen: Zentrum für didaktische Studien.

Markowsky, R. \& Thomas, A. (1995). Studienhalber in Deutschland - Interkulturelles Orientierungstraining für amerikanische Studenten, Schüler und Praktikanten. Heidelberg: Asanger.

Müller, A. \& Thomas, A. (1995). Studienhalber in den USA - Interkulturelles Orientierungstraining für deutsche Studenten, Schüler und Praktikanten. Heidelberg: Asanger.

Schroll-Machl, S. (1996). Kulturbedingte Unterschiede im Problemlöseprozeß bei deutsch-amerikanischen Arbeitsgruppen. In A. Thomas (Hrsg.), Psychologie interkulturellen Handelns (S. 383-409). Göttingen: Hogrefe.

Schroll-Machl, S. (2000a). Bipolare Kulturstandardpaare im deutsch-tschechischen Kulturvergleich der Wirtschaftskooperation. Regensburg: Dissertation.

Schroll-Machl, S. \& Nový, J. (2000b). Perfekt geplant oder genial improvisiert? Kulturelle Unterschiede in der deutsch-tschechischen Zusammenarbeit. München: Hampp Verlag.

Stumpf, S. \& Thomas, A. (Eds.). (2000). Diversity and group effectiveness. Lengerich: Pabst Verlag.

Thomas, A. (1993). Psychologie interkulturellen Lernens und Handelns. In A. Thomas (Hrsg.), Kulturvergleichende Psychologie - Eine Einführung (S. 377-424). Göttingen: Hogrefe.

Triandis, H.C. (1975). Culture training, cognitive complexity and interpersonal attitudes. In R. W. Brislin, S. Bochner \& W.J. Lonner (Eds.), Cross-cultural perspectives on learning (pp. 39 - 77). New York: Wiley.

Zeutschel, U. (1999). Interkulturelle Synergie auf dem Weg: Erkenntnisse aus deutsch/ U.S.amerikanischen Problemlösegruppen. Gruppendynamik, 30 (2). 